\title{
THE EFFECT OF SOCIO-ECONOMIC \& DEMOGRAPHIC DETERMINANTS ON CHILDREN'S SOLID FOOD-INTAKE IN INDIA: A STUDY BASED ON NFHS-4
}

\author{
Madhubrota Chatterjee, PhD scholar, Population Research Centre, Institute for \\ Social and Economic Change, Bangalore, India.
}

\begin{abstract}
:
Better access to nutrition improves the health and generates overall development. Children should receive proper nutritious food from the very initial stage which will help them in their rapid process of growth and development. In these vital phase, India witness huge discrimination in allocating solid food that can range from a child's age to gender. In this paper, I have looked upon the solid food-intake inequality among the children in India during 6 to 59 months of age, with the help of various responsible determinants using NFHS round 4 data. The results show enough gender discrimination among female children in the allocation of supplemental food, along with discontinued early breastfeeding.
\end{abstract}

\section{INTRODUCTION:}

Nutrition is a critical part of health and development. Better access to it results in improved infant, child, maternal health, stronger immune systems, safer pregnancy and childbirth, lower risk of non-communicable diseases, and longevity. Early childhood is a period of rapid growth and discrimination against female children contributes significantly to excess female mortality in India, which has led to millions of 'missing' women (Agarwal, C. 1994). A preference for sons over daughters, and its causes and consequences have generated considerable research in Indian phenomena and have shown some direct links with nutrition. Although many studies have shown this great extent of gender discrimination, very little focus has been given to the solid food intake among children, which is the fundamental point of their entire growth and development. Eating behaviours evolve during the first years of life and the children learn what, when, and how much to eat through the direct experiences with food, and also by observing 
the eating behaviour of others. Complimentary food should be introduced around the age of 6 months, and in case if they are provided with an inappropriate amount, an infant's growth may delay. Therefore this study will analyze the solid food-intake inequality among the children in India during 6 to 59 months of age, with the help of various responsible determinants.

\section{REVIEW OF THE LITERATURE:}

Girls are less likely than boys to receive supplemental food and more likely to be malnourished. In general, it appears that higher women's status within a community, as well as higher maternal status, have beneficial effects on a daughter's nutritional status. Furthermore, there is evidence supporting gender discrimination against female children in the allocation of supplemental foods and the prevalence of malnutrition. The fixed effects show that among currently breastfeeding children below the age of two years, females are $15 \%$ less likely than males to receive supplemental milk-based solid foods. They are $21 \%$ less likely than males to receive any of the more valued meat, fish, or eggs. Girls are also 7\% more likely than boys to suffer from malnutrition. Gender differences vary across communities (Bose, Sunita. 2017). Fathers and mothers act differently towards their children and fathers act in a more kind of indulgent way and exert less active control in food intake. Early life experiences of food intake with various tastes and favours have a role in promoting healthy eating and wider consumption. Currently, parental food habits, housing characteristics, and feeding strategies are the most dominant determinants of a child's eating behaviour and food choices (Scaglioni et al., 2018). Kulsum et al. (2008) in their study showed that only $22 \%$ of children enjoyed a diet adequate in protein and calories. Protein calorie adequacy is influenced by the age and gender of children and significantly by the literacy or economic status of mothers. Mother's nutritional status influenced protein-energy adequacy of diets significantly. High nutritional risk varied considerably according to age group and gender, mainly in the case of females. Variables associated with increased nutritional risk were: under 24 years of age, being female, low social class, low educational level of the mother, and having more than one sibling. Most nutritional studies performed during childhood and adolescence in developed countries report intakes falling below recommendations in a significant percentage of the population. Lack of physical activity and inadequate food choices have been proposed as the principal determinants of this phenomenon (Ribas et al. 2002). Mothers who are aware of the outcomes of certain eating behaviours, or who work with the specific intention of promoting certain food intake in their 
children, reported that their children eat higher levels of healthier food items, such as fruits, vegetables, and salad. It, therefore, follows that mothers who use a feeding strategy, tend to have higher levels of healthier food intake themselves. One important element of this is for the child to see the parent eating the food, laying emphasis on the parent trying to encourage the child to eat. Mothers who ate more meals with their children reported higher levels of food intake among their children. In addition, shared breakfasts and dinner times both seem to be important in producing the opportunity for this feeding behaviour to occur (Palfreyman, 2012).

\section{RESEARCH OBJECTIVE:}

- To examine the effect of possible socio-economic and demographic factors on the differences in solid food intake among children in India.

\section{RESEARCH QUESTION:}

- Is there any relationship between the household's demographic characteristics and food intake among the children in India?

- How the economic factors affect the children's food intake?

- What is the impact of maternal status on the children's food intake?

\section{METHODOLOGY:}

\section{Data}

Data for this analysis were obtained from the National Family Health Survey, 2015-16 (Round4). NFHS follows the format of DHS, which is a large-scale household survey conducted in Asia, Africa, and Latin America. NFHS-4 used four questionnaires: the Women's Questionnaire, which asked for detailed health and demographic information from women in their reproductive years, including information about their children; the Household Questionnaire, which included demographic and socioeconomic information on respondents' households; Men's Questionnaire, and Biomarker Questionnaire for assessing the health situation among them. It provides consistent and reliable estimates of Fertility, Mortality, Family planning, Health, Health care utilization, Nutrition, Reproductive Health, Morbidity, Women empowerment, Domestic violence, HIV knowledge and behaviour, and all other 
related indicators at the National, State and for the very first time, in District levels also (IIPS, 2017).

The NFHS-4 asks mothers whether the children from 0 to 59 months of age had any solid or semi-solid food in the past 24 hours. According to the American Academy of Paediatrics (AAP), solid food among children should start between 4 to 6 months of age. Therefore I used the sample of children dataset born to ever-married 13- to 49-year-old women and merged it across the Women's dataset. Children's age from 6 to 59 months were taken into consideration for being a vital period to have solid food, and also little gender discrimination seems to occur in infancy (Bhuiya., Streatfield. 1992; Muhuri., Preston. 1991).

\section{Outcome Variables}

The outcome variables are divided into three solid food categories: Milk products coded as (1 for children who received Cheese, Yogurt, Fats, Butter, or other Milk products in the last 24 hours and 0 for all who did not). Meat, Fish, Egg coded as ( 1 for those who received these food and 0 for those who did not). Vegetables coded as ( 1 for those who received them and 0 who did not). The total number comprises 2, 21,858 children in 6 to 59 months of age, and out of this 83,417 children were taken into consideration in my study sample for consuming these three types of solid food.

\section{Explanatory Variables}

To see the association of these three categories of solid food intake, several explanatory variables were taken into consideration, dividing them into three-four broad characteristics. In a child's characteristics, Gender is a key dichotomous variable, coded 1 if the child was female. Children from 6 to 59 months who are currently under breastfeeding are coded as 1 being breastfed and 0 for those who do not. Caste is categorized in General, Scheduled Caste, Scheduled Tribe, and Other Backward Castes. The region is divided into North, South, East, and West considering the states under places. The region was particularly important, given the historically strong regional patterns of preferences for sons and gender differences in child mortality in India. The household wealth index is categorized as Poorest, poorer, Middle, Richer and Richest, according to the NFHS-4 report. Under the mother's characteristics, I included Mother's education ( 1 if educated and 0 for not), working status ( 1 if the mother is 
working, 0 if not), and autonomy. In the NFHS-4, seven questions measure women's autonomy. Four items tap into women's decision-making power and ask who makes the following decisions: decisions about health care for yourself, making major household purchases, making purchases for daily household needs, and visiting family or relatives. Three questions for their mobility freedom like: On whether they are usually allowed to go to the market, the health facility, and places outside the village/community. Access to media ( 1 if the family has the access to radio, TV, and newspaper). Apart from these, there were Father's education and work which were taken into consideration, along with the Mother's food intake on those respective food intakes for the children.

The description for all the explanatory variables in the form of a table is given below:

\section{Description of Independent variables:}

\section{Independent variables}

\section{Description}

Gender

Currently breastfeeding

Religion

Region

Caste

Place of Residence

Household wealth index

Mother's education

Mother's working status

Mother's autonomy

Media influence

Family size

Ante-natal care

Father's education

Father's work

Mother's food intake
Categorical $(0=$ Male and $1=$ Female $)$

Categorical $(0=$ Not being breastfed, $1=$ breastfed $)$

Categorical (Hindu=1, Muslim=2, Others=3)

Categorical (North=1, South=2, East=3, West=4)

Categorical $(1=$ Others, $2=\mathrm{SC}, 3=\mathrm{ST}, 4=\mathrm{OBC})$

Categorical (1= Urban, 2= Rural)

Categorical (Poorest, Poorer, Middle, Richer, Richest)

Categorical (No education $=0$,Education $=1$ )

Categorical (Working $=1$, Not working $=2$ )

Categorical $(1=$ With autonomy, $0=$ not $)$

Categorical ( $1=$ Families having access to TV, newspaper, radio and $0=$ not $)$

Categorical ( $1=$ with 1 children, $2=2,3=3$ and above)

Categorical (YES=1, $\mathrm{NO}=2$ )

Categorical (No education $=0$,Education $=1$ )

Categorical (Working $=1$, Not working=2)

Categorical (1= Daily and Occasionally and 2= Never)

\section{Statistical analysis:}

All the Statistical Analysis has been performed using the STATA version- 16.

I used Binary Logistic Regression, also known as the Logit model, which is used to model dichotomous outcome variables. This is because all my three dependent variables are coded into dummy variables, i.e. 1 and 0 , and is shown in the forms of the odds ratio and $95 \%$ Confidence intervals. An odds ratio is used to measure the association between the exposure 
and outcome variables. It represents whether an outcome will occur given for particular exposure, compared to the odds of occurring in the absence of that exposure.

The formula for basic binary logistic regression is defined by:

$\operatorname{Logit}(y)=\ln ($ Odds $)=\ln (\mathrm{P} / 1-\mathrm{P})=\alpha+\beta x$

Where $\mathrm{P}$ is the probability of an interesting outcome and $\mathrm{x}$ is the explanatory variable. The parameters of logistics are $\alpha$ and $\beta$.

Table 1: Description of Dependent variables with sample size:

\begin{tabular}{lcc}
\hline \multicolumn{1}{c}{ Dependent variables } & Sample & $\mathbf{N}$ \\
\hline Milk products & $6-59$ months & $18,052(14.6)$ \\
Meat, Fish, Egg & $6-59$ months & $18,348(14.91)$ \\
Vegetables & $6-59$ months & $47,017(38.03)$ \\
& Total & 83,417 \\
\hline
\end{tabular}

\section{RESULTS:}

Table 1 gives a picture of all the children from 6 to 59 months taken for studying the allocation of solid food given to them. Vegetable consumption comes first among the children, followed by valued supplemental meat, fish, egg, and milk products. Vegetables are easily available, most beneficial, and common in all households.

Table 2 shows the logistic regression between the children under 6 to 59 months of age consuming milk products and the socio-economic and demographic determinants to determine their association with each other. Compared to gender, male children as kept in the reference category, female children are 0.07 times less likely consumes milk and milk products. Children who are currently being breasted are 0.5 times less likely to consume supplemental milk products than those who do not. In the religion category, Muslim families are 0.7 times less likely to feed their children with these products. Similarly less consumption in the regions of East, West, and Central India as compared to Northern India. Among the household wealth index, all the wealth strata are impacting the consumption, taking the poorest category in the reference section. Education, work, and autonomy are very important to determine the intake association. Mothers who are educated, working, and have autonomy regarding decisionmaking are significantly associated with supplemental milk product intake. Similarly, media influence and paternal work affect the outcome. Family size, i.e. the living children in the family of 1 and 2 are more likely to affect the food consumption, compared to the family size of 3 and above. Mothers who got their ante-natal care are 1.3 times more likely to feed their 
children with milk products. Those mothers who frequently take milk products are more likely to give their children the same.

Table 2: Binary Logistic Regression in the form of Odds ratio for the consumption of milk products with possible determinants.

\begin{tabular}{|c|c|c|c|}
\hline \multirow{2}{*}{$\begin{array}{c}\text { Background characteristics } \\
\text { Female child }\end{array}$} & \multirow{2}{*}{$\begin{array}{c}\text { Odds ratio } \\
0.072 * *\end{array}$} & \multicolumn{2}{|c|}{ 95\% Confidence Interval } \\
\hline & & 0.914 & 1.259 \\
\hline Currently breastfeeding & $0.553 * *$ & 0.455 & 0.674 \\
\hline \multicolumn{4}{|l|}{ Religion } \\
\hline Muslim & $0.737 * *$ & 0.503 & 1.083 \\
\hline Others & 1.589 & 1.179 & 2.142 \\
\hline \multicolumn{4}{|l|}{ Caste } \\
\hline $\mathrm{SC}$ & 1.113 & 0.853 & 1.452 \\
\hline $\mathrm{ST}$ & $0.877 * *$ & 0.622 & 1.238 \\
\hline OBC & 1.032 & 0.844 & 1.263 \\
\hline \multicolumn{4}{|l|}{ Region } \\
\hline East & $0.661 * *$ & 0.467 & 0.937 \\
\hline Central & $0.678 * *$ & 0.527 & 0.853 \\
\hline West & $0.444 * *$ & 0.331 & 0.596 \\
\hline \multicolumn{4}{|l|}{ Residence } \\
\hline Rural & 1.164 & 0.956 & 1.416 \\
\hline \multicolumn{4}{|l|}{ Household wealth index } \\
\hline Poorer & $1.62 * *$ & 1.124 & 2.342 \\
\hline Middle & $2.654 * *$ & 1.824 & 3.863 \\
\hline Richer & $2.498 * *$ & 1.667 & 3.746 \\
\hline Richest & $3.874 * *$ & 2.536 & 5.920 \\
\hline Mother's education & $0.813 * *$ & 0.522 & 1.019 \\
\hline Mother's work & $1.323 * *$ & 0.622 & 1.064 \\
\hline Mother's autonomy & $1.350 * *$ & 0.546 & 1.107 \\
\hline Media influence & $1.337 * *$ & 1.050 & 1.668 \\
\hline Ante-natal care & $1.281 * *$ & 1.037 & 1.588 \\
\hline \multicolumn{4}{|l|}{ Family size } \\
\hline 2 & 1.071 & 0.886 & 1.294 \\
\hline 3 and above & $0.739 * *$ & 0.584 & 0.937 \\
\hline Father's education & 0.715 & 0.692 & 1.450 \\
\hline Father's work & $0.803 * *$ & 0.594 & 1.109 \\
\hline \multicolumn{4}{|l|}{ Maternal food intake } \\
\hline Milk products & $1.445 * *$ & 0.491 & 1.043 \\
\hline
\end{tabular}

NOTE: - **: significant $(\mathrm{p}<0.05)$ 
Table 3 depicts the logistic regression among the children under 6 to 59 months of age consuming meat, fish, and egg with the possible socio-economic and demographic determinants. Results show that almost all the explanatory variables are statistically significant in terms of their non-vegetarian food consumption, throwing light on their correlation and association. Those factors which did not show any statistical significance are the Ante-natal care for the mothers and father's education in the family. Female children are 0.8 times less likely given the valued meat, fish, and egg. Compared to urban areas, rural places of residence are less followed with this category of food consumption. Family size with more than 3 are less likely to consume meat, fish, egg compared to the size of 1 and 2. Mothers who consume meat, fish, and egg on an occasional or daily basis are 1.2 times more likely to feed their babies with the same food, compared to those mothers who do not.

Table 3: Binary Logistic Regression in the form of Odds ratio for the consumption of Meat, Fish, and Egg with possible determinants.

\begin{tabular}{|c|c|c|c|}
\hline \multirow{2}{*}{$\begin{array}{c}\text { Background characteristics } \\
\text { Female child }\end{array}$} & \multirow{2}{*}{$\begin{array}{l}\text { Odds ratio } \\
0.829 * *\end{array}$} & \multicolumn{2}{|c|}{ 95\% Confidence Interval } \\
\hline & & 0.634 & 1.085 \\
\hline Currently breastfeeding & $0.497 * *$ & 0.354 & 0.698 \\
\hline \multicolumn{4}{|l|}{ Religion } \\
\hline Muslim & $0.962 * *$ & 0.662 & 1.401 \\
\hline Others & $1.308 * *$ & 0.844 & 2.029 \\
\hline \multicolumn{4}{|l|}{ Caste } \\
\hline $\mathrm{SC}$ & $0.828 * *$ & 0.505 & 1.359 \\
\hline $\mathrm{ST}$ & $0.798 * *$ & 0.503 & 1.269 \\
\hline $\mathrm{OBC}$ & 0.861 & 0.596 & 1.246 \\
\hline \multicolumn{4}{|l|}{ Region } \\
\hline East & $2.977 * *$ & 1.828 & 4.849 \\
\hline Central & $2.870 * *$ & 1.838 & 4.484 \\
\hline West & $0.993 * *$ & 0.539 & 1.833 \\
\hline \multicolumn{4}{|l|}{ Residence } \\
\hline Rural & $0.725 * *$ & 0.533 & 0.987 \\
\hline \multicolumn{4}{|l|}{ Household wealth index } \\
\hline poorer & $1.917 * *$ & 1.059 & 3.471 \\
\hline middle & $2.632 * *$ & 1.434 & 4.831 \\
\hline richer & $2.361 * *$ & 1.234 & 4.519 \\
\hline richest & $2.145^{* *}$ & 1.057 & 4.355 \\
\hline Mother's education & $0.513 * *$ & 0.282 & 0.937 \\
\hline Mother's work & $1.046^{* *}$ & 0.292 & 0.798 \\
\hline Mother's autonomy & $1.183 * *$ & 0.233 & 0.820 \\
\hline Media influence & $1.321 * *$ & 0.700 & 1.566 \\
\hline Ante-natal care & 0.860 & 0.654 & 1.132 \\
\hline
\end{tabular}


Family size

\begin{tabular}{llll}
\multicolumn{1}{c}{\begin{tabular}{ll}
\multicolumn{1}{c}{ 3 and above } \\
Father's education
\end{tabular}} & $1.015^{* *}$ & 0.803 & 2.175 \\
Father's work & $0.839^{* *}$ & 0.736 & 1.401 \\
$\begin{array}{l}\text { Maternal food intake } \\
\quad \text { Milk, Fish, Egg }\end{array}$ & $1.509 * *$ & 0.574 & 1.228 \\
$\quad$ & $1.162 * *$ & 0.835 & 2.729 \\
\hline
\end{tabular}

NOTE: - **: significant $(\mathrm{p}<0.05)$

Table 4 illustrates the binary logistic regression for the children aged 6 to 59 months of age, who are consumed with vegetables along with their possible socio-economic and demographic determinants. Results depict that female children under this age, as compared to the male children are 0.9 times less likely to get feed with vegetables. Among the children who are currently under breastfeeding practice are 0.6 times less likely to consume vegetables. Under the caste category, none of the sections shows any statistically significant association for consuming vegetables. Compared to the urban area, rural areas are less likely to maintain this association. Compared to the other wealth categories like rich and middle, children from the poorer sections of the society are more likely to consume vegetables. Mothers who are educated and consuming vegetables on a daily or occasional basis are more involved in feeding their children with regular vegetables. Other factors like Antenatal care, working mothers, father's work and education, media influences did not show any relevant statistical relation.

Table 4: Binary Logistic Regression in the form of Odds ratio for the consumption of Vegetables with possible determinants.

\begin{tabular}{|c|c|c|c|}
\hline Background characteristics & Odds ratio & \multicolumn{2}{|c|}{$\mathbf{9 5 \%}$ Confidence Interval } \\
\hline Female child & $0.979 * *$ & 0.863 & 1.111 \\
\hline Currently breastfeeding & $0.590 * *$ & 0.499 & 0.698 \\
\hline \multicolumn{4}{|l|}{ Religion } \\
\hline Muslim & $0.646 * *$ & 0.480 & 0.870 \\
\hline Others & $0.954 * *$ & 0.725 & 1.257 \\
\hline \multicolumn{4}{|l|}{ Caste } \\
\hline $\mathrm{SC}$ & 1.155 & 0.932 & 1.431 \\
\hline ST & 0.938 & 0.728 & 1.208 \\
\hline OBC & 0.941 & 0.800 & 1.108 \\
\hline \multicolumn{4}{|l|}{ Region } \\
\hline East & $1.637 * *$ & 1.282 & 2.092 \\
\hline Central & $1.317 * *$ & 1.101 & 1.575 \\
\hline West & $1.241 * *$ & 1.013 & 1.521 \\
\hline
\end{tabular}




\section{Residence}
Rural
0.938
0.799
1.101

Household wealth index

$\begin{array}{lccc}\text { poorer } & 1.262^{* *} & 1.004 & 1.588 \\ \text { middle } & 1.139 & 0.885 & 1.464 \\ \text { richer } & 1.113 & 0.843 & 1.469 \\ \text { richest } & 1.250 & 0.925 & 1.688 \\ \text { education } & 1.257^{* *} & 0.680 & 1.125 \\ \text { work } & 0.839 & 1.024 & 1.544 \\ \text { autonomy } & 1.137 & 1.253 & 2.211 \\ \text { luence } & 0.973 & 0.692 & 1.017\end{array}$

Mother's education

Mother's work

0.973

0.692

1.017

Family size

2

0.986

0.799

1.185

3 and above

0.874

0.982

1.315

Father's education

1.056

0.845

1.150

Father's work

0.943

0.730

1.047

Maternal food intake

Vegetables

$1.358 * *$

0.715

1.244

NOTE: - **: significant $(\mathrm{p}<0.05)$

\section{DISCUSSION AND CONCLUSION:}

This paper emphasizes the role of socio-economic and demographic factors in studying the solid food intake differences among children in India. A food supplement is a preparation that is intended to supply a nutrient that is missing from a diet. The age group of 6 to 59 months is very crucial to consider, as it is regarded as the vital period for introducing children to solid food items. This study is hypothesized to have no serious relationship between the food intakes for children and the responsible determinants into consideration.

The regression supports enough gender discrimination among female children in the allocation of supplemental food. They are $0.07,0.8$, and 0.9 times less likely to receive milk products, any valued meat, fish, egg, and vegetables respectively. Breast milk is also an important source of energy and nutrients in children aged 6-23 months and most of the existing reports worldwide tell them to continue breastfeeding, even after the age of 12 months. It can provide half or more of a child's energy needs between the ages of 6 and 12 months, and one-third of energy needs between 12 and 24 months. Breast milk is also a critical source of energy and nutrients during illness and reduces mortality among children who are malnourished (WHO, 2020). Currently breastfed children from 6 to 59 months of age, shown in the findings, are provided with solid food somehow less than those who are not. The particular association of 
meat, fish, and egg with the factors influencing has clear statistical importance, depicting that this valued food is hard to consume for some households. Children from rural areas are less consuming the valued meat, fish, egg as compared to the urban areas. One of the findings says that rural stores tend to have higher food prices, lower quality fresh foods, and less variety than urban stores (Bitto et al, 2006). Looking at the region divided based on zones, compared to the Northern areas, all the other parts such as Central, West, and Eastern areas have a direct association with these food intakes. It can be because of their easy availability, staple food habits, and cultural differences. Mother's education, work, and autonomy have a significant relationship with the food allocation to their children. Women's status, particularly maternal status, affects the gender difference in supplemental foods. Women with greater autonomy would have more knowledge as well as control of resources that could affect the well-being of their children in a positive way. Educated and working mothers are more likely focused on giving their children the best nutrients they deserve. Another important finding was the family size, where 3 children and above in a family are less likely to receive supplemental meat, fish, egg. This finding may be related to the responsibility of having to prepare meals or to less attention being given to food or individuals in families with a larger number of children (Gregory, 2000). Father's education, on the other side, does not show any significant relation with the food intake but their work is somehow related as in most of the Indian families, fathers are the sole breadwinner. Media influence is more both in the allocation of meat, fish, egg, and milk products to the children. Studies showed that the effect of media is because of all the foodrelated advertisements put up on Social media, Televisions, and Newspapers. Studies exhibited that a strong desire for TV food ads and the enthusiasm for different TV programs like cartoons especially, can affect the food intake in children. There is a relationship between interest in watching TV advertising and an increase in cereals intake. In addition, meats intake in children interested in TV advertising was higher than the uninterested ones (Kalantari et al, 2016). As the family meals information in my secondary data is not available, the maternal food intake is taken into consideration. The results appropriately depicted that mothers who daily and occasionally eat supplemental meat, fish, egg, vegetables, and milk products give their children the same. Plus, a child's eating habit is shaped by observing what their parents eat in the house.

While it is important to focus on the improvements in women's status as a way to reduce neglect, it is also important to take into account the amount and quality of such improvements. Low levels of female education or work for low pay is not enough to reduce the unequal 
treatment of sons versus daughters in particular, and their children in general. Public policy planners must work to improve the overall status of women within a community through gender empowerment programs that encourage more education, higher decision-making abilities, and more supplemental income for women. The results suggest that while household wealth accumulation is indeed an important driver of diversification, women's education, family size, and the food environment in the family are likely to play an additional independent role as well. Access to maternal and child health care may also play an important role in how children are fed, and highlighting the opportunities to improve the nutritional messaging of conventional health services.

\section{LIMITATIONS:}

NFHS gives information on the single 24-hour food intake for child and frequency for mothers in their questionnaire which is less precise than more time-intensive forms of dietary assessment and might help to study the young children's food habit which is particularly important for their physical and cognitive development

\section{REFERENCES}

Africa, N. (2003). NUTRITION AND IMMUNIZATION IN RURAL INDIA : THE ROLE OF SIBLINGS *. 40(3), 395-418.

Bose, S. (2011). of Biosocial Science: THE EFFECT OF WOMEN'S S STATUS AND COMMUNITY ON THE GENDER DIFFERENTIAL IN CHILDREN'S NUTRITION IN INDIA. 513-533. https://doi.org/10.1017/S002193201100006X

Factors Influencing Children's Eating Behaviours_Enhanced Reader.pdf. (n.d.).

Garcı, R., \& Javier, P. (2002). Determinants of Nutrient Intake among Children and Adolescents: Results from the enKid Study. 46(suppl 1), 31-38. https://doi.org/10.1159/000066398

Kulsum, A., Ja, L., \& Prakash, J. (2008). Food Intake and Energy Protein Adequacy of Children from an Urban Slum in Mysore, India - a Qualitative Analysis. 14(2), 163-172.

Palfreyman, Z., Haycraft, E., \& Meyer, C. (2012). Original Article Development of the Parental Modelling of Eating Behaviours Scale ( PARM ): links with food intake among children and their mothers. 1-13. https://doi.org/10.1111/j.1740-8709.2012.00438.x 
International Institute for Population Sciences (IIPS) \& ORC Macro (2000) National Family Health Survey (NFHS-2), 1998-99: India. IIPS, Mumbai.

Basu, A., Roy, S. K., Mukhopadhyay, B., Bharati, P., Gupta, R. \& Majumdar, P. P. (1986) Sex bias in intrahousehold food distribution: roles of ethnicity and socioeconomic characteristics. Current Anthropology 27(5), 536-539. 